Kohl: a Journal for Body and Gender Research Vol. 3, No. 2 (Winter 2017)

\title{
Talking Sex as a Necessity
}

Ghiwa Sayegh 
I don't fuck. Not anymore. Not very often at least. Not with the normative finality of an in and out or an up and down, slow, sensual, frenzied. Not when it is spontaneous and unexpected, like the sudden thunderstorm in the August heat, almost an accident. Not when bodies that touch, that pinch, slap, pull, drag, and squeeze, that hurt and are hurt, when minds that probe, that inquire, that ravage and devour, are all reduced to quirky enhancements to compulsory intercourse. I don't fuck despite my desire to fuck - a desire that inevitably subsides to a general feeling of noncommittal annoyance after two meager thrusts, when its fulfillment becomes certainty. I don't fuck, but I do have sex. Sexual interactions that I plan and negotiate for - I am no "surprise" enthusiast - with the same thoroughness that editing a text would require. I get off on/(to) details.

My sex is not radical. ${ }^{1}$ It is not subversive, despite its unrespectability. Not when it is exoticized, produced as a marker of progress, as a daring demonstration to be hailed - there is nothing revolutionary about my locality, except in imaginaries that see the world in binaries. Not when it is met with the pitying concerns of those who want to save me from my desires, the badly-concealed glee of those who salivate at the prospect of medicalizing them, and the sneer of those who seek to distance themselves from their filthy deviancies. Not even when I casually let out an "I have my period" or a "my pap smears is due soon" at a family gathering, to the horrified, silent glares of the attendance.

I like to amuse myself by imagining how far I would fall from Gayle Rubin's respectability sex line, ${ }^{2}$ embodied by the imposing structure of a brick wall. Its sheer visuality is reminiscent of Sara Ahmed's reading of walls ${ }^{3}$ as "what you come up against, [...] a physical contact; a visceral encounter" (136). Throughout the years, through that "sex hierarchy" that separates good sex from bad sex, the "normal" from the "abnormal," the "healthy" from the "sick," with a grey "area of contest" in between (Rubin 154), I could not but notice that my position vis-à-vis the wall was never static. And although my patterns were erratic, shaped by encounters, intimacies, fluctuations, I could never cross. One time, my sex fell very close to the wall line, so close that I could imagine what crossing the barrier of respectability would feel like; I could almost inhale it, the promise of "moral complexity" as opposed to my presumably "utterly repulsive and devoid of all emotional nuance" predicament (152) invading my lungs. I was in constant motion, but the wall itself seemed immutable, "a materialism that shows how history becomes concrete" (Ahmed 136), too concrete for noticeable erosion to take place. For some of us, our sex, a foreverpathology, is too assertive in its woman-ness, too non-binary, too queer, too "perverted," too complex for the wall to make space for us.

And yet, I still find myself able to talk about my sex, in private, in semi-public spheres, in public talks, in published texts that I pen with my own name. I can still toy with the boundaries of what is acceptable and push for reactions to better challenge and deconstruct. I can still carve spaces and intimacies for myself in the communities that fall short of the respectability wall. If my sex still allows me to navigate spaces across the board, albeit ambiguously at times, if its "dirtiness" still cannot trouble the sociopolitical understanding of what is "clean" and "acceptable," there must be, then, other dimensions at play. I could talk all I want about consent sought at every turn, but there is nothing inherently radical about the sex of

\footnotetext{
${ }^{1}$ As employed by Yasmin Nair in her blog piece "Your Sex Is Not Radical."

2 Rubin, Gayle S. "Thinking Sex: Notes for a Radical Theory of the Politics of Sexuality." Culture, Society, and Sexuality: A Reader, edited by Richard Guy Parker and Peter Aggleton. Psychology Press, 1999, pp. 143-178.

${ }^{3}$ Ahmed, Sara. Living a Feminist Life. Duke University Press, 2017.
} 
a cis-gendered, middle class, non-migrant "citizen," no matter how non-normative it might be. So many times, my sex becomes an "unfortunate" anomaly that can be overlooked, other lines of respectability making up for it. Echoing Sara Ahmed, "what for some are ordinary bumps for others are walls" (181). As we manoeuver different walls of respectability, it is their intersections that harden crossings. When we do not encounter walls at every turn, certain walls become permeable to some. If "a wall becomes necessary because the wrong bodies could pass through" (145), then it takes more than non-normative sex to embody a "wrong" body.

Our sex is not radical. Not when it exists in a political vacuum. Not when it aspires to move "into the direction of respectability" (Rubin 152). Not when crossing becomes its sole finality. And it is in this linear, unidirectional crossing, this desire to move our sex from "filthy" to "respectable," that we leave the binary untouched; we look for structures made porous for us. In these acts of dual crossings, we leave others behind with the promise of eventual porosity; that the walls that are permeable for us will be permeable for them, if they only identified with our own categories for the sake of unity. The leap from sex to orientation, from desire to identity cannot be washed down with the guarantee of acceptance to all. Legitimacy aside, identities based on our sex could not, should not become universal markers of sameness. If our sex is the only factor that brings us together, if walls that harden for some of us are belittled or deemed fictitious, if others' struggles are stepped on, passed over in favor of the oh-so coveted badge of respectability, then how can we link arms in the fight for justice and change? Identities that operate in binaries push for recognition; they strive to represent diversity but call for political unity; they claim to be different but demand respectability. Where respectability becomes the goal, complicity becomes its commodity. We must work towards the dismantling of walls as structural, as systemic, not as hurdles to overcome. And in that vein, we must create a new language; we must envision new ways of being in the world that acknowledge that we do not fight the same fights, even if our sex seemingly intersects.

It is within this race for crossing the respectability line, framed as progress, that some of us have had their sex disavowed, covertly or ferociously. If and when our sex impeded that race, we were slut-shamed for not conforming to the duality of the non-monogamous, long-term couple; we were slut-shamed again for having "too much" sex; we were called prudes for having "too little" sex; we were objectified for choosing to display our bodies, our bodies in turn becoming public arenas of harassment that was argued to "not be motivated by desire;" we were met with disgust for our kinks, with derision for our partners' age, with contempt for making sex our currency, with reticence for our mental health. And perhaps because of our presumed similarity did this disavowal become a site of trauma, of resistance. Perhaps because of it does the composition of sex, desire, and intimacy lose its elasticity under the burden of fixed identities. But sex is not always synonymous to fucking; desire is not always conducive to sexual behaviors or to identity formations, and intimacy is not always sexual or romantic. If our sex is not radical as a stand-alone practice, it is the collapsing of the sex, desire, and intimacy triad that we need to talk about.

Sex is not a luxury, ${ }^{4}$ and neither is talking about it. But those of us who attempt to render sex discursive are often rebutted with claims to temporal inadequacy. "Now is not the time," we are told, as if our lives

\footnotetext{
${ }^{4}$ Non-luxury and necessity as employed by Audre Lorde in:
} 
were not multidimensional and complex, as if our sex did not intersect with the grand quests of liberation, as if we had to flaccidly sit on the sidelines, waiting for our post-scriptum liberations to be authorized, while others busy themselves with making the world a habitable place for us, even though we had no say in its habitability. But the claims of women and gender non-conforming individuals are too uncomfortable to be dealt with as legitimate, too complex to be timely, too pressing to be heard. And it is this dissociation of struggles, this prioritizing of politics, this assumptive ranking of needs that relegate sex to luxurious consumptions and unworthy pursuits. Queering sex that is work, care, emotional labor, that is casual, filthy, kinky, that intersects with violence, social class, race, migration status, becomes, then, a necessity, ${ }^{5}$ a site of struggle.

Sex deemed unrespectable and untimely seldom makes a worthy research question. At least where our contexts are concerned - the focus of my venture, research looks for a "nobility" in sex that identity formations can aliment. Research on sex is vastly reduced to research on identity, with the leap from sex to identity providing the necessary framework for a worthy cause that can only be constructed in opposition to a filthier, unworthy counterpart. The sanitization of sex, then, maintains the respectability line of research and the academe, further hardening walls, histories, and the bodies they leave out. This sanitary erasure, so entrenched in a male gaze towards sex, crossings, and liberation, needs to be challenged and uprooted from its binary, reformist yearnings. And until our hard-earned histories are accounted for, we will persevere in the fight for our dirty sex, our aberrant desires, our deviant intimacies, and their unrespectable multitude.

Lorde, Audre. "Poetry Is Not a Luxury." Sister Outsider, 1984. Polity Press, 2007, pp. 36-39.

${ }^{5}$ Idem. 